\title{
Ollier Disease at the Origin of a Cervical Spinal Cord Compression: About a Case and Review of Literature
}

\author{
Belgacem I*, Habchi N, Aggar S, Benmouma Y and Djaafer M \\ Neurosurgery Department CHU Mustapha BACHA Algiers, Algeria
}

Submission: April 20, 2019; Published: May 09, 2019

*Corresponding author: Belgacem I, Neurosurgery Department CHU Mustapha BACHA Algiers, Algeria

\begin{abstract}
Enchondromatosis or "Ollier disease" is a rare genetic disease, it corresponds to a benign bone dysplasia whose evolution towards the neoplastic degeneration is known, touching preferentially the bones of the hand, the bones of the skeleton axial, as well as the craniofacial massif. We report the case of enchondromatosis causing cervical spinal cord compression in a 27-year-old female who was referred to our department for the treatment of tetraparesis. CT of the cervical spine revealed a basicervical heterogeneous calcified lesion infiltrating the neighbouring bone and spinal MRI confirms the mass effect on the spinal cord. The patient was operated on and the lesion was removed in total, the histopathological examination retained the diagnosis of enchondromatosis.

Keywords: Enchondromatosis; Ollier Disease; Spinal Cord Compression;
\end{abstract}

\section{Introduction}

Ollier disease represents 1.2 to $2.4 \%$ of benign bone tumors $[1,2]$, it affects preferentially the bones of the hand, the axial skeleton, the foot, then come the femur, the humerus, the forearm, pelvis and craniofacial massif [3]. In our study the involvement concerned the long bones of the upper and lower limbs, as well as the cervical spine.

\section{Observation}

Young woman aged 27 operated on an anterior forearm mass, whose results were inconclusive, 17 years later, the patient consults for a progressive installation of a tetraparesis for 2 months with appearance of a posterior cervical mass evolving in the last 5 years. Clinical examination found two masses: one at the posterior cervical level painfully limited painful $25 \mathrm{~cm}$ long axis, hard to palpate motionless and without inflammatory sign opposite; and the other mass is at the level of the anterior aspect of the inferior extremity of the left thigh. The neurological examination found a spastic tetraparesis without genito sphincteric disorders.

The standard radio of the mass of the anterior face of the lower extremity of the femur objectified image in racket (Figure 1). The CT examination of the cervical spine revealed a basicervical heterogeneous calcified lesion, larger on the left with areas of infiltration and bone lysis invading the vertebral canal causing a mass effect on the spinal cord (Figure 2). The patient benefited from a cervical MRI which objectified a well-defined heteroge neous left posterolateral basicervical lesion in T1 and T2, taking strongly the contrast product and infiltrating the soft parts and the adjacent bone structure, causing a spinal cord compression in relation to C6 and C7 (Figure 3).

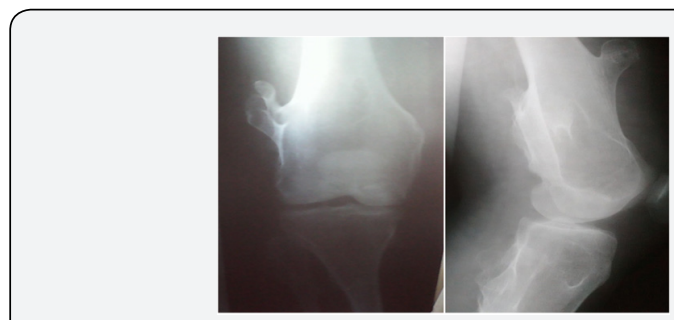

Figure 1: Standard X-ray of the lower extremity of the femur: bone density injury in racket.

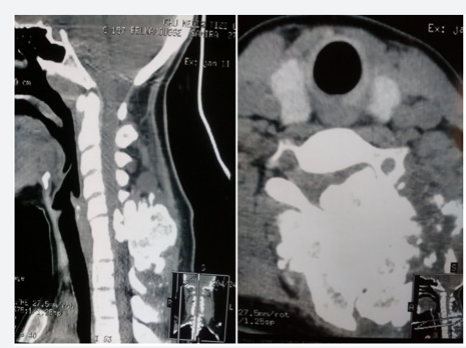

Figure 2: Scan of the cervical spine showing a basicervical heterogeneous calcified lesion invading the spinal canal and compressing the spinal cord. 


\section{Psychology and Behavioral Science International Journal}

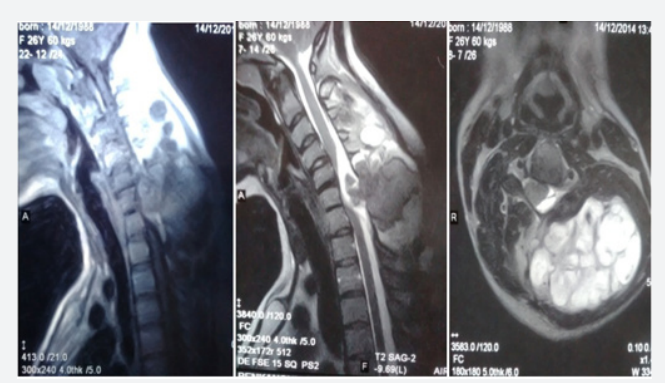

Figure 3: Cervical MRI in sagittal section in T1 and T1 post gado and $\mathrm{T} 2$ and axial section.

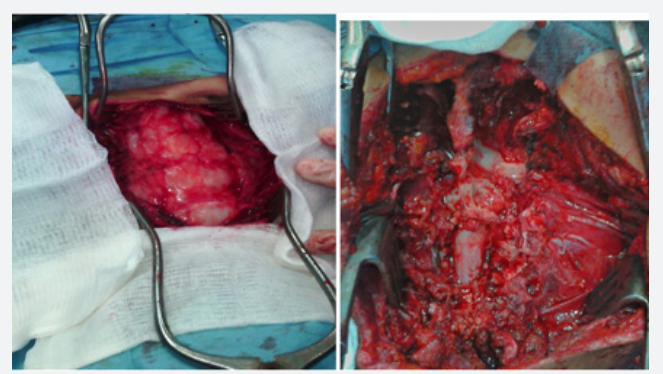

Figure 4: Pre and post operative images.

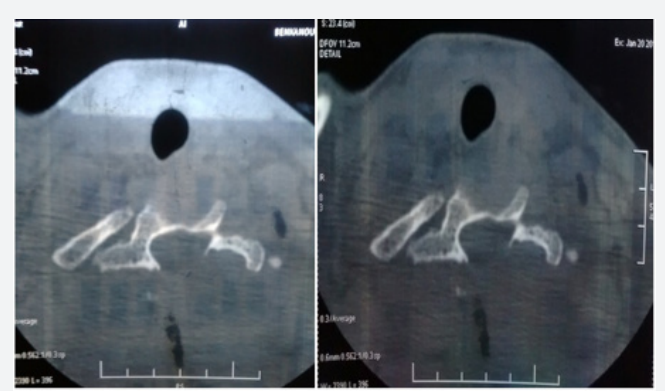

Figure 5: Post operative cervical CT.

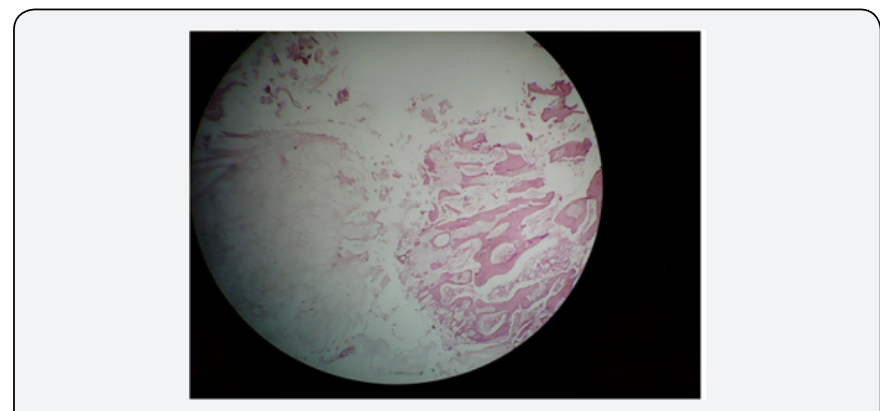

Figure 6: Pathological study of the osteochondroma.

The lesion was approached by median posterior surgical pathway: after cutaneous incision, the lesion appeared in pearly white, hard, infiltrating the musculoaponeurotic masses; the removal of the infiltrating portion of the bone was completed with a C6-C7 laminectomy which decompressed the spinal cord (Figure 4). Postoperative cervical CT shows good bone marrow decompression (Figure 5). The postoperative course was good with total neurological recovery after a few functional rehabilitation sessions. Pathological study showed a benign mesenchymal proliferation of nodular form, it is made of a cartilaginous cap containing regular chondrocytes. In depth, there are bony trabeculae delimiting the spaces which contain vascularized adipose tissue: the aspect is in favour of an osteochondroma (Figure 6).

\section{Discussion}

The ollier disease, also known as disseminated chondromatosis, is named after the physician who described it at the beginning of the century $[3,4]$. It is a constitutional, non-hereditary, rare disease whose etiology is unknown. It is characterized by growth dysplasia in which hypertrophic cartilage is neither resorbed nor normally ossified and often develops unilaterally [1-5]. There are multiple benign tumors that form from the cartilage, the enchondromas. The latter may be of different number, size and location, explaining the extreme clinical variability between the carriers of this disease. The attacks are generally predominant on one side. The association of Ollier disease with hemangiomas is called Maffucci syndrome [6,7].

Enchondromatosis is a rare genetic disease that accounts for 1.2 to $2.4 \%$ of benign bone tumors. The incidence at birth is estimated at 1 in 100,000 [2]. They are discovered at the early age of life, typically during the first 3 decades and they increase in volume during the growth of the skeleton, then stabilize, which corresponds to our case where the discovery was made at the age of 9 years $[2,3,8]$. The locations are often asymmetrical, not systematized and sometimes only one member is affected [monomelics] and it is to these that we reserve the name of Ollier disease, often in hemi-somatic form ( $50 \%$ of cases according to the authors) [2].

The chondromes preferentially touch the tubular bones of the hand and foot and then come the femur, the leg, the humerus, the forearm and the pelvis [6]. The bones of the axial skeleton are also affected as well as the craniofacial massif. The elbow, the bones of membranous ossification, the bones of carp and tarsus seem to have been spared by the disease.

In our study, sickness involved the long bones of the lower limb (femur), upper limb (forearm) and cervical spine. The incidence of degenerative risk of chondroma during Ollier disease is highly variable. It is estimated between 2.5 and $50 \%$ depending on the series $[1,3]$. It remains nevertheless of less importance than in Maffucci's disease where the neoplastic degeneration seems almost inevitable marked by the frequent appearance of the tumors of the mesenchymatous tissues (chondrosarcomas, fibrosarcomas, angiosarcomas) as well as various malignant lesions (carcinomas, astrocytomas). Surgery is the only effective therapeutic option and can be conservative [8-11]. It can be enough on its own to get a cure. If inoperability, radiation and chemotherapy used as therapeutic alternatives, have a very low efficiencies, in terms of slow-growing tumors. The prognosis, which depends on the location of the lesion, its size, the number of foci and local control, is relatively favorable but recurrence occurs in 25 to $50 \%$ of cases $[2,12,13]$. 


\section{Conclusion}

Enchondromatosis or "Ollier disease" is a rare genetic disease. It corresponds to benign bone dysplasia, affecting preferentially the bones of the hand, the bones of the axial skeleton, as well as the craniofacial mass. Diagnosis is based on precise and coupled analysis of clinical, epidemiological, radiological and histological criteria. Therapeutically, these lesions are often accessible to conservative treatment, the emergence of spinal cord compression in the presence of urgent neurological signs is mandatory. Nevertheless, the problematic of this pathology remains dominated by the possibility of sarcomatous transformation and the great difficulty of differential diagnosis between chondroma and chondrosarcoma of low grade.

\section{References}

1. Brazrer DJ, Roberts-Hary J, Crockard A (1993) Intercavernous chondrosarcoma associated with ollier's disease. Br J Ophtulmol 599-600.

2. Hasbini A, Lartigau E, Le Péchoux C, Acharki A, Vanel D, Genin, et al. (1998) À propos de deux cas et revue de la literature. Cancer/ Radiothérapie 2(4): 387-391.

3. Pfleiderer AG, Thomson P, Milroy CM (1991) View from Beneath, pathology in focus: ENT presentation of Ollier's disease. J Laryngol Otol 105: 148-150.
4. Damron TA, Sim FH, Unni KK (1996) Multicentric chondrosarcomas. Clin Orthop Relat Res 328: 211-219.

5. Liu J, Hudkins PG, Swee RG, Unni KK (1987) Bone sarcomas associated with ollier's disease. Cancer 59: 1376-1385.

6. Dellagi K, Micheau C, Estelm R, Genin J (1985) Chondrome nasal associé à une maladie d'ollier. A propos d'un cas observe a l'institut Gustave-Roussy. Ann Oto Laryngol 102: 537-541.

7. Schwartz HS, Zimmerman NB, Simon MA, Wroble RR, Millar EA, et al. (1987) The malignant potential of enchondromatosis. J Bone Joint Surg 69: 269-274.

8. Campanacci M (1990) Central chondrosarcoma. In: Bone and soj tissue tumor, Springer Verlag; New York, USA, pp. 265-343.

9. Gitelis S, Bertoni F, Picci P, Companacci M (1981) Chondrosarcoma of bone. The experience at the Institut ortopedica Rizzoli. J Bone Joint Surg 63: 1248-1256.

10. Grenspan A (1989) Tumors of cartilage origin. Orthop Clin North Am 20: $347-366$.

11. Horn J (1994) Chondrosarcoma of bone: oncologic and functional results. J Surg Oncol 57: 214-221

12. Cannon SR, Sweetmm DR (1985) Multiple chondrosarcomas in dyschon-droplasia (Oilier's disease) Cancer 55: 836-834.

13. Healy JH, Lane JH (1986) Chondrosarcoma. Clin Orthop Relat Res 204: 119-129.

\section{Your next submission with Juniper Publishers will reach you the below assets}

- Quality Editorial service

- Swift Peer Review

- Reprints availability

- E-prints Service

- Manuscript Podcast for convenient understanding

- Global attainment for your research

- Manuscript accessibility in different formats

( Pdf, E-pub, Full Text, Audio)

- Unceasing customer service

Track the below URL for one-step submission https://juniperpublishers.com/online-submission.php 